fractive index, melting point $175^{\circ}$. On standing in the air, the crystals assume a slight yellow tinge.

Diphenylacridane can also be prepared by adding zinc dust to a boiling solution of diphenylacridol in acetic acid. The free radical, diphenylacridyl, is formed as an intermediate product, as is shown by the instantaneous production of a deep red color on adding the zinc dust. If the boiling is continued for some time with the occasional addition of zinc dust to the acid solution, the red color will be gradually discharged to a pale yellow. On pouring the acetic acid solution into water acidulated with hydrochloric acid, the diphenylacridane precipitates as colorless flakes. These, on drying and recrystallizing from ligroin, show the same properties as given above.

Calc. for $\mathrm{C}_{18} \mathrm{H}_{28} \mathrm{~N}: \mathrm{C}$, $90.04 ; \mathrm{H}, 5.75$; found: 89.75 and 6.00 .

Molecular weight: Calculated, 333; found: $33 \mathrm{I}$ in boiling chloroform.

Analogues of Diphenylacridyl.-The following analogues of diphenylacridol have been prepared and from them, salts, free radicals and peroxides, have been obtained: $p$-chlorophenyl- $N$-phenylacridol, $p$-methoxyphenyl$N$-phenylacridol, 2,4-dimethoxyphenyl- $N$-phenylacridol, phenyl- $N$-methyl acridol, phenyl- $N$-ethylacridol. So far as studied, the salts of all of these acridols behave essentially as do the salts of diphenylacridol. In each case the watery solutions of the salts give a free, dark brownish red radical with zinc dust. All of these free radicals are soluble in benzene and in solution are readily oxidized to form peroxides. The salts having aliphatic radicals attached to the nitrogen atom tend to yield more of the acridane and less of the free radical than the aryl nitrogen acridyl salts. The free radicals and the peroxides obtained above will be described in the next paper.

ANN ARBor, MrCh.

\title{
THE PREPARATION OF RAFFINOSE.
}

BY C. S. Hudson and T. S. Harding. 1

Received August 4, 1914.

In the course of an investigation on the hydrolysis of raffinose by enzymes, it became necessary to prepare several kilograms of the sugar. A method which was devised for the purpose has proved materially preferable to the procedures recorded in the literature and its description may be useful to those requiring a supply of raffinose.

\section{Selection of the Best Natural Source for Raffinose.}

It is recorded that crystalline raffinose has been isolated from Australian

${ }^{1}$ Contribution from the Carbohydrate Laboratory, Bureau of Chemistry, Department of Agriculture. 
eucalyptus manna, ${ }^{1}$ cottonseed, ${ }^{2}$ beet molasses, ${ }^{3}$ barley, ${ }^{4}$ wheat, ${ }^{5}$ and the leaves of the yew ${ }^{6}$ (Taxus baccata L.). The crystallization of raffinose from eucalyptus manna appears to have been readily accomplished, and with as high a yield as $60 \%$, but we are informed by correspondents in Australia ${ }^{7}$ that the manna is difficult to obtain in quantity. Beet molasses, barley, and wheat, though easily obtained, contain considerable quantities of sugars other than raffinose and in consequence its crystallization from these sources is difficult and the yield small. The yield of raffinose from the leaves of the yew appears to be very small. On the other hand, cottonseed is a very satisfactory source because it is readily obtained, is inexpensive, contains several per cent. of raffinose and does not contain other sugars or interfering substances in sufficient proportion to prevent a rapid crystallization of the raffinose from the purified and concentrated extract of the seed. Upon inquiry of manufacturers, we learn that most of the raffinose which is prepared for the chemical market is made from this natural source.

Cottonseed can best be used for this preparation in the form of cottonseed meal, which is the ground press cake that remains after the oil has been expressed from the hulled seed. Cottonseed meal is extensively used as a cattle food and fertilizer and may be purchased from feed merchants.

\section{Methods of Ritthausen and of Zitkowski for Preparing Raffinose from Cottonseed Meal.}

Ritthausen was able to obtain a yield of from I to $2.5 \%$ of crystalline raffinose from cottonseed meal by extracting the latter with warm $80 \%$ alcohol, evaporating the solvent, extracting coloring matter and oil from the residue with ether, precipitating impurities from the aqueous solution of the residue with lead acetate, removing the excess lead as sulfide, and concentrating the solution to a syrup, which crystallized on keeping at about zero during one or two weeks. When this process is carried out on a large laboratory scale, it has been our experience that it is expensive and inconvenient, on account of the extractions with alcohol and ether. The yield is also unsatisfactory because cottonseed meal contains on the average $6-8 \%$ of raffinose, judging from the polarimetric reading of the extract.

${ }^{1}$ Johnston, Phil. Mag., 23, I4 (1843); Berthelot, Ann. chim. phys., 46, 66 (1856); Tollens, Ber., 18, 26II (1885); Passmore, Pharm. J. Trans., 2I, 717 (1890).

2 Ritthausen, J. prakt. Chem., 29, 391 (1884); Böhn, Archiv. pharm., [3] 22, 159 (1884).

${ }^{3}$ Loiseau, Compt. rend., 82, 1058 (1876).

${ }^{4}$ O'Sullivan, J. Chem. Soc., 49, 7o (1886).

S Schulze and Frankfurt, Ber., 27, 64 (I894).

${ }^{\complement}$ Hérissey and Lefebvre, $J$. pharm. Chim., [6] 26, 56 (rgo7).

'Anderson \& Co., Ltd., Seedsmen, of Sydney, New South Wales. 
Zitkowski ${ }^{1}$ has prepared raffinose from cottonseed meal by extracting the latter with water, pressing the extract from the meal, making it alkaline with lime and filtering, precipitating the raffinose at a low temperature in a special cooling and stirring apparatus with powdered lime, and regenerating the raffinose from its insoluble lime compound by carbonating. After evaporation to a syrup, there slowly crystallized at a low temperature about $0.8 \%$ of raffinose. Although this method avoids extractions with alcohol or ether, the yield is very low, and in repeating the process, it has been our experience that it is difficult to carry out, though we succeeded in obtaining a yield of about $\mathrm{I} \%$ of low grade raffinose.

\section{An Improved Method for Crystallizing Raffinose from Cottonseed Meal.}

The following is a description of a procedure by which we have prepared, in the laboratory at different times, about 5 kilograms of raffinose from various samples of commercial cottonseed meal with a yield of 2.5 to $4 \%$.

One kilo of meal is mixed with 5 liters of tap water and filtered with suction on a large Büchner funnel as quickly as possible, because a delay of fifteen minutes or more may cause the meal to become too slimy for filtration. The sugar contained in the meal dissolves very readily in cold water and the meal may be washed on the funnel with cold water until the filtrate shows no optical rotation. To the combined filtrates there is added the usual basic lead acetate solution ${ }^{2}$ in slight excess, which requires about I cc. for each $5 \mathrm{~g}$. of meal. The yellow lead precipitate is removed by slow filtration over night through paper ${ }^{3}$ and is washed in the morning, after transference to a Büchner funnel, until the washings show no rotation. The combined filtrates should be brilliantly clear and of a light yellow color. The excess of lead is next removed as lead sulfide, after saturating with hydrogen sulfide gas. It will be found that the filtrate is slightly acid and is colorless, but regains its yellow tint if made alkaline, showing that the color is due to a natural indicator. A measurement of the optical rotation and volume of the solution at this stage will indicate the presence of about $80 \mathrm{~g}$. of raffinose (anhydrous $\mathrm{C}_{18} \mathrm{H}_{32} \mathrm{O}_{16}$, specific rotation $[\alpha]_{\mathrm{D}}=$ $+{ }_{123}$ ), on the assumption that the rotation is due only to raffinose. In support of this assumption, it may be said that reducing sugars are present only in traces and no sugar except raffinose has so far been detected. There is then added to the solution about $0.2 \mathrm{~g}$. of sodium hydrosulfite 4 to prevent development of color and it is boiled under reduced pressure in glass to a syrup of about $25 \%$ water content, which should have no more than a slight yellowish color.

1 "American Sugar Industry," Sept., Igro, page 324.

" Prepared, for example, according to the directions in U. S. Dept. Agr., Bur. Chem., Bull. 107, p. 40, or Browne, "Handbook of Sugar Analysis," p. 208.

${ }^{3}$ In working with large quantities, it would probably be advantageous to use a bag filter.

${ }^{4}$ See Browne, "Handbook of Sugar Analysis," p. 221. 
It has proved very advantageous at this stage to follow a modification of the procedure of Gunning ${ }^{1}$ in the preparation of barium raffinosate. Barium hydroxide is added to the syrup in the proportion of $2 \mathrm{~g}$. of the octahydrate to each gram of raffinose and the solution is completed by warming to not over $80^{\circ}$ for a few minutes, fifteen usually being sufficient. The mixture is gradually poured into one and a half times its volume of anhydrous methyl alcohol ${ }^{2}$ contained in a large mortar, and the barium raffinosate, which precipitates as a granular compound, is ground to a fine powder, filtered off, and washed with methyl alcohol. Ethyl alcohol (95\%) has been successfully used in place of methyl for the precipitation of this compound but it comes down more quickly and cleanly and is more readily decomposed later if methyl alcohol is used. The barium compound is suspended in about $1500 \mathrm{cc}$. of distilled water and decomposed by the gradual addition of $50 \%$ phosphoric acid solution, care being taken to reach exact neutrality at the end of the process. The voluminous precipitate of barium phosphate is filtered off with suction and is thoroughly washed until the filtrate has no rotation. The solution should be of a light yellowish brown color at this stage. Since the barium phosphate is slightly soluble, it has been found necessary to precipitate the last traces of barium with sulfuric acid and filter. A redetermination of the volume and optical rotation of the solution at this stage will show the extent to which the raffinose has been recovered from the barium compound. With ordinary precautions, the yield is $95 \%$ of the theoretical but yields of $98-99 \%$ are not unusual. Fifty grams of eponite ${ }^{3}$ are mixed with the solution and the latter is filtered in a few minutes, since little advantage results from long standing or heating. The filtrate is still yellow in color, which, however, does not interfere with subsequent crystallization. The solution is next boiled in vacuo to a light straw colored syrup of about 20 to $25 \%$ water content and there is added just to saturation $95 \%$ ethyl alcohol, containing $0.3 \%$ nitric acid, about 10 to $15 \mathrm{cc}$. being usually required. This acidification of the alcohol has proved useful for the purpose of avoiding high ash content in the crystalline raffinose. The mixture is then seeded with crystals of raffinose hydrate and set away at $0^{\circ}$ to crystallize over night. In the morning the solid mass of crystals is ground with $75 \%$ ethyl alcohol in a mortar, filtered off with suction, and washed with the same strength alcohol until the washings are colorless. The yield is about $40 \mathrm{~g}$. of colorless raffinose crystals, and it may be increased to $\mathrm{g}$. by working over the mother liquor a second time through the barium hydroxide purification. The chief impurity in this raffinose is an ash

${ }^{1}$ Bull. de l'assaciation Belge de chim., 4, 318 (189o).

${ }^{2} \mathrm{~A}$ commercial anhydrous grade which may be purchased for about eighty cents per gallon.

${ }^{3} \mathrm{~A}$ recently introduced vegetable carbon of high purifying power which may be purchased of dealers in chemical supplies. 
content of 0.5 to $1 \%$ which may be removed by recrystallization. For this purpose a 50\% aqueous solution of the crystals is prepared, filtered, and to it is added the previously mentioned acidified alcohol, nearly to cloudiness, and the solution stirred. Crystallization of raffinose hydrate is rapid at room temperature and the crystals, which may be washed first with $75 \%$ and later with $95 \%$ alcohol, contain less than $0.05 \%$ ash, give a specific rotation of $123.2^{\circ}$ (anhydrous sugar) in 10\% aqueous solution at $20^{\circ}$, and the yield is about $2.5 \%$ of the weight of the original meal. A further crystallization of $0.5 \%$ of equally pure raffinose may be obtained by cooling the mother liquor to zero.

Bureau of Chgmistry,

DEPARTMENT OF AORICULTURE,

Washington, D. C.

[CONTRIBUtion from the LABoratory of Agricultural Chemistry of the UniVERSITY OF WISCONSIN.]

THE OCCURRENCE OF METHYL ALCOHOL IN CORN SILAGE. By E. B. HaRt and A. R. Lamb. Received August 4, 1914.

In I9I2, Hart and Willaman published a paper on the volatile fatty acids and alcohols of corn silage. ${ }^{1}$ From the data secured in the separation of the alcohols by the Duclaux method, it was concluded that corn silage contains, besides ethyl and propyl alcohols, a small amount of methyl alcohol. The quantity found may be approximately expressed as $0.05 \%$ of the silage mass, or about $20 \mathrm{~g}$. in Ioo pounds of silage.

In the same year there appeared a paper by Dox and Neidig, ${ }^{2}$ in which the main conclusions of Hart and Willaman were substantiated, but which did not agree on the presence of methyl alcohol. The question of the occurrence of methyl alcohol in corn silage is therefore taken up in this paper.

\section{Experimental Part.}

There are numerous methods in the literature, of varying degrees of reliability, for the detection of methyl in the presence of ethyl alcohol. Many of these were tested with various known mixtures of alcohols, and only those which appeared always to be trustworthy were used. Of these, the Trillat test, ${ }^{3}$ and the resorcin test, as modified by Scudder, ${ }^{4}$ seemed to be most reliable. The gallic acid test, ${ }^{5}$ the morphine test, ${ }^{6}$ the phenol test, ${ }^{7}$ the Haigh phloroglucin test, which is discussed by Scudder, ${ }^{8}$ and

1 This Journal, 34, 1619 (1912).

${ }^{2}$ Research Bull. 7, Iowa Expt. Sta.

3 Bull. ro7, Bureau of Chem., p. 99.

4 ThIS JoURNAL, 27, 892.

'Ann. de Chim. analyt. appl., 4, I56 (I899).

' Hinkel, Analyst, 33, 417.

7 Leach, "Food Inspection and Analysis," 2d ed., p. 820.

${ }^{8}$ Loc. cit. 